\title{
Comparison of bowel function after ileorectal anastomosis for ulcerative colitis and colonic polyposis
}

\author{
C. R. NEWTON ${ }^{1}$ AND W. N. W. BAKER \\ From the Research Department, St Mark's Hospital, London, and the Department of Surgery, Gordon Hospital, \\ London
}

SUMMARY Bowel habit has been studied in a group of 92 outpatients with ileorectal anastomosis for ulcerative colitis and compared with that in a group of $\mathbf{4 5}$ outpatiencs with ileorectal anastomosis for colonic polyposis. Bowel frequency ranged from 1.7 to 8.7 stools per 24 hours with a mean of 4.5 in the colitic group compared with a range of 1.3 to 8.1 stools per 24 hours and a mean of 3.5 in the polyposis group. Eighty-two per cent of the colitic group and $95 \%$ of the polyposis group had six or fewer bowel actions per 24 hours. Colitic patients in poor general condition at the time of colectomy seemed more likely to have over six bowel actions per 24 hours than those less severely ill. Urgency of defaecation was rare. Bowel actions every night and occasional faecal incontinence occurred in small but similar percentages of patients in both groups. Fifty-one per cent of patients in the colitic group, as compared with $9 \%$ in the polyposis group, were taking regular treatment to improve bowel function.

Dietary difficulty was rare after ileorectal anastomosis in both colitic and polyposis groups.

Although there are several reports of the number of bowel actions per day experienced by patients after ileorectal anastomosis for ulcerative colitis (Aylett, 1966, 1970; Jagelman, Lewis, and Rowe-Jones, 1969; Clemmesen and Sprechler, 1970; Nedbal, Maratka, and Novak, 1970; Watts and Hughes, 1970) and colonic polyposis (Boehme, 1950; Lockhart-Mummery, Dukes, and Bussey, 1956; Williams and Wightman 1966), there has been no attempt to document in detail and compare bowel function in patients who have had the operation for these two conditions. There is also no report of the incidence of dietary intolerance after ileorectal anastomosis, as described for ileostomists by Thomson, Runcie, and Khan (1970).

The object of this study was to provide these data, determining the range of bowel habit after ileorectal anastomosis for ulcerative colitis and comparing it with that after ileorectal anastomosis for colonic polyposis. The association of specific aspects of bowel function with the medical and surgical history, the incidence of drug taking to improve

${ }^{1}$ Present address: The Middlesex Hospital, London W1N 8AA.

Received for publication 9 July 1975 , bowel function and intolerance to a wide range of foodstuffs were also assessed.

\section{Method}

Outpatients, who had had an ileorectal anastomosis for histologically confirmed ulcerative colitis or colonic polyposis six months or more before and were attending for routine follow up at St Mark's or the Gordon Hospital during 1971-1972, were seen by one or other of us. All such patients attending St Mark's Hospital with ileorectal anastomosis for ulcerative colitis during 1971 took part. Patients at the Gordon Hospital were seen during a continuous four-month period in 1971-1972. As it was impossible to interview all the patients seen in this outpatient clinic, the hospital notes of all the patients who attended were subsequently examined to determine whether those seen were a particularly selected group. The notes of the patients seen at St Mark's Hospital were also examined and compared. Preoperative assessment of the clinical severity of colitis and criteria for colectomy were classified in a similar way to that described by Ewart and Lennard-Jones (1960). Patients were placed in group A if they were in good general condition with inactive colitis and had an 
elective colectomy because of chronic ill health, local complications or the risk of cancer. Group B consisted of patients in good general condition with active colitis at the time of colectomy, who had the operation electively for the same reasons as in group $\mathrm{A}$ or because of failure of medical treatment. Group C consisted of patients in poor general condition with active colitis whose colectomy was nevertheless elective, while group D consisted of those severely ill patients in whom colectomy was carried out urgently or as an emergency. Histological activity and the extent of colitis were determined from the pathologist's report on the colectomy specimen. Extent was classified as total where the whole colon and caecum were involved, 'extensive' where colitis affected the colon at least to the hepatic flexure, and 'left-sided' where colitis did not extend beyond the transverse colon. The incidence of active inflammation in the rectum at the time of ileorectal anastomosis, both clinically and histologically, was determined. The current state of health recorded at that outpatient appointment and the number of attendances in the previous 12 months, in those who had had their ileorectal anastomosis for at least 18 months, were also noted.

Patients with ileorectal anastomosis for colonic polyposis were seen during a continuous 12-month period in 1971-1972, although a few were missed on an entirely random basis.

Each of the patients seen was questioned to determine the incidence of urgency of defaecation, faecal incontinence, drug taking, body weight changes and difficulty in choosing a diet. To assess specific dietary intolerance, the patient was asked if he had noted watery stools, flatulence or pain following a list of 23 common foodstuffs or any items of diet not included in the list. The patient was then asked to keep a stool chart at home, noting down the time of each bowel action for seven consecutive days, and post it back to St Mark's Hospital in the stamped addressed envelope provided. The patient's hospital notes were examined to determine if bowel frequency, urgency of defaecation or faecal incontinence was associated with particular preoperative, operative or postoperative factors. In the patients with ileorectal anastomosis for ulcerative colitis seen at St Mark's Hospital, bowel frequency, urgency and incontinence were also compared with sigmoidoscopic appearance and rectal biopsy histology, where available, at the time of study.

\section{Results}

One hundred and thirty-seven patients were interviewed, 92 with ileorectal anastomosis for ulcerative colitis and 45 with ileorectal anastomosis for colonic polyposis. Eighty-eight per cent of the patients completed the stool chart successfully. Table I shows the age, sex distribution and time interval since ileorectal anastomosis in the two groups.

\begin{tabular}{lll}
\hline & \multicolumn{2}{l}{ Uleurectal Anastomosis for } \\
\cline { 2 - 3 } & Ulcerative Colitis & Colonic Polyposis \\
\hline $\begin{array}{l}\text { No. of patients } \\
\text { Age (yr) }\end{array}$ & 92 & 45 \\
$\quad$ Range & $19-67$ & $20-72$ \\
$\quad$ Mean & 42.5 & $42 \cdot 1$ \\
$\begin{array}{l}\text { Sex } \\
\text { Male }\end{array}$ & 43 & 30 \\
$\quad$ Female & 49 & 15 \\
$\begin{array}{l}\text { Interval since operation } \\
\quad \text { Range }\end{array}$ & $6 \mathrm{mth}-17 \mathrm{yr}$ & $6 \mathrm{mth}-24 \mathrm{yr}$ \\
$\quad$ Mean & $8 \cdot 1 \mathrm{yr}$ & $12 \cdot 7 \mathrm{yr}$ \\
\hline
\end{tabular}

Table I Number of patients seen with age, sex distribution and time interval since ileorectal anastomosis

A further 43 patients attending the Gordon Hospital with ileorectal anastomosis for ulcerative colitis were not interviewed during the period of study. They differed little from those seen in age (range 20-69 years, mean 45.9 years), sex distribution (18 male, 25 female) or time interval since ileorectal anastomosis (range six months-19 years, mean 8.0 years).

Table II shows the results of the study of hospital notes, comparing patients at St Mark's Hospital with those at the Gordon Hospital who were seen and those who were not seen during the study. This shows that over $80 \%$ of the patients had total colitis active histologically at the time of colectomy. There was little difference between the three groups of patients in duration of colitis before colectomy, clinical staging at colectomy, extent or activity of colitis in the resected colon or inflammation of the rectum at ileorectal anastomosis. The outpatient note on the 43 patients at the Gordon Hospital who were not seen records that all were well as regards bowel function, with the exception of three patients who were complaining of a recent bout of diarrhoea and one who was under investigation for symptoms of intestinal obstruction. One of those seen was complaining of a recent bout of diarrhoea. There was little difference in the average number of outpatient attendances in the previous 12 months in the three groups.

Table III shows the results of the bowel function study in the patients seen with ileorectal anastomosis for ulcerative colitis and colonic polyposis. An average bowel frequency per 24 hours was calculated for each patient from the seven-day stool chart. 


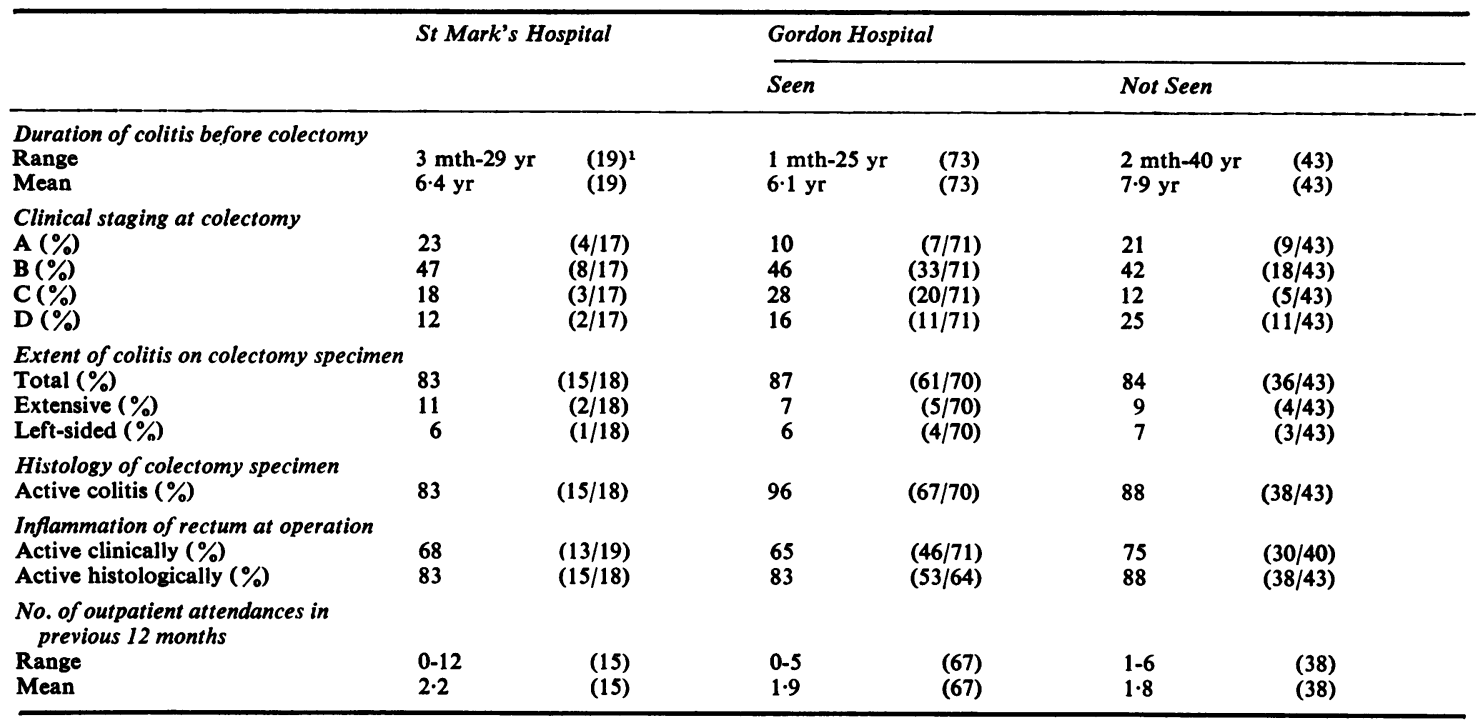

Table II Comparison of patients seen with those not seen during the study of ileorectal anastomosis for ulcerative colitis

${ }^{1}$ Number of patients in parentheses from which figures are derived.

Bowel frequency ranged from 1.7 to 8.7 per 24 hours with a mean of 4.5 in the colitic group, compared with a range of 1.3 to 8.1 per 24 hours and a mean of 3.5 in the polyposis group. An average of six or fewer bowel actions per day was found in $82 \%$ of the colitic group and $95 \%$ of the polyposis group.

The need to get up at night for a bowel action was assessed by calculating the number of patients who had a bowel action between 12 midnight and 6 am on the seven-day stool chart. Although $70 \%$ of the colitic group and $49 \%$ of the polyposis group had a bowel action on at least one night of the study, only 4 and $5 \%$ of the two groups got up every night.

Urgency of defaecation, assessed by asking the patient how long he could delay a bowel action if he were out, was no problem in the majority of patients and $78 \%$ of the colitic group and $83 \%$ of the polyposis group were able to delay defaecation 30 minutes or longer. Only $4 \%$ of the colitic group

\begin{tabular}{|c|c|c|c|c|}
\hline \multirow{2}{*}{ Bowel frequency/24 hours } & \multicolumn{4}{|c|}{ Ileorectal Anastomosis for } \\
\hline & \multicolumn{2}{|c|}{ Ulcerative Colitis } & \multicolumn{2}{|c|}{ Colonic Polyposis } \\
\hline $\begin{array}{l}\text { Range } \\
\text { Mean }\end{array}$ & $\begin{array}{l}1 \cdot 7 \cdot 8 \cdot 7 \\
4 \cdot 5\end{array}$ & $\begin{array}{l}(78)^{1} \\
(78)\end{array}$ & $\begin{array}{l}1 \cdot 3-8 \cdot 1 \\
3 \cdot 5\end{array}$ & $\begin{array}{l}(43) \\
(43)\end{array}$ \\
\hline $\begin{array}{l}\text { Less than } 3 \text { bowel actions } \\
\text { 3-6 bowel actions } \\
\text { More than } 6 \text { bowel actions }\end{array}$ & $\begin{array}{l}23 \% \\
59 \% \\
18 \%\end{array}$ & $\begin{array}{l}(18 / 78) \\
(46 / 78) \\
(14 / 78)\end{array}$ & $\begin{array}{l}44 \% \\
51 \% \\
5 \%\end{array}$ & $\begin{array}{r}(19 / 43) \\
(22 / 43) \\
(2 / 43)\end{array}$ \\
\hline $\begin{array}{l}\text { Defaecation between midnight and } 6 \text { am } \\
\text { At least one night in study } \\
\text { All nights in study }\end{array}$ & $\begin{array}{r}70 \% \\
4 \%\end{array}$ & $\begin{array}{r}(55 / 78) \\
(3 / 78)\end{array}$ & $\begin{array}{l}49 \% \\
5 \%\end{array}$ & $\begin{array}{r}(21 / 43) \\
(2 / 43)\end{array}$ \\
\hline $\begin{array}{l}\text { Ability to delay defaecation } \\
30 \text { minutes or longer } \\
\text { Less than } 5 \text { minutes }\end{array}$ & $\begin{array}{r}78 \% \\
4 \%\end{array}$ & $\begin{array}{r}(71 / 91) \\
(4 / 91)\end{array}$ & $\begin{array}{r}83 \% \\
0 \%\end{array}$ & $\begin{array}{r}(33 / 40) \\
(0 / 40)\end{array}$ \\
\hline $\begin{array}{l}\text { Faecal incontinence in previous } 12 \text { months } \\
\text { All patients } \\
\text { Patients less than } 2 \text { years after operatipn } \\
\text { Patients more than } 2 \text { years after operation }\end{array}$ & $\begin{array}{l}17 \% \\
31 \% \\
15 \%\end{array}$ & $\begin{array}{r}(16 / 92) \\
(4 / 13) \\
(12 / 79)\end{array}$ & $\begin{array}{l}22 \% \\
33 \% \\
21 \%\end{array}$ & $\begin{array}{l}(9 / 41) \\
(1 / 3) \\
(8 / 38)\end{array}$ \\
\hline $\begin{array}{l}\text { Medications } \\
\text { Regular treatment to improve bowel function } \\
\text { Treatment for rectal inflammation }\end{array}$ & $\begin{array}{r}51 \% \\
9 \%\end{array}$ & $\begin{array}{r}(47 / 92) \\
(8 / 92)\end{array}$ & $9 \%$ & $(4 / 45)$ \\
\hline
\end{tabular}

Table III Bowel function after ileorectal anastomosis for ulcerative colitis and colonic polyposis

${ }^{1}$ Number of patients in parentheses from which figures are derived. 
could delay defaecation for less than five minutes.

An episode of major faecal incontinence had occurred in the previous 12 months in $17 \%$ of the colitic group and $22 \%$ of the polyposis group. It was less common in patients who had had an anastomosis for more than two years.

Codeine phosphate and/or Isogel, or less commonly Celevac, Lomotil and a variety of anticholinergics were taken regularly by $51 \%$ of the colitic group and $9 \%$ of the polyposis group. One patient in each group took liquid paraffin to prevent constipation. Nine per cent of the colitic group were taking treatment for rectal inflammation.

Table IV shows the results of the study of hospital notes in the patients with ileorectal anastomosis for ulcerative colitis, comparing bowel frequency with preoperative, operative and postoperative factors. In those patients with more than six bowel actions per 24 hours at the time of study, a higher percentage $(71 \%)$ were in poor general condition preoperatively (clinical categories $\mathrm{C}$ and $\mathrm{D}$ ) than in the groups with three to six bowel actions per 24 hours $(37 \%)$ and less than three bowel actions per 24 hours $(24 \%)$. The percentage with total colitis, histologically active at the time of colectomy, also increased somewhat with increasing bowel frequency. There was, however, little difference between the three bowel frequency groups in duration of colitis preoperatively, staging of surgery, incidence of leakage at the ileorectal anastomosis, time interval since the anastomosis or the later occurrence of intestinal obstruction, perianal disease (perianal abscess or fistula-in-ano) or ano-rectal stricture.

The same preoperative, operative and postoperative factors were analysed separately in the 20 patients with urgency, who were unable to delay defaecation for 30 minutes, the 16 patients who had suffered an episode of faecal incontinence in the previous 12 months and the seven patients with both urgency and incontinence. When compared with the whole group of 92 patients with ileorectal anastomosis for ulcerative colitis, no factor was particularly associated with urgency or incontinence with the exception of ano-rectal stricture, which was present in $19 \%(3 / 16)$ of those with incontinence compared with $4 \%(3 / 76)$ of those without, although ano-rectal stricture was not present in any of the patients with urgency.

Table V shows the comparison of bowel function with activity of rectal inflammation at sigmoido-

\begin{tabular}{|c|c|c|c|c|c|c|}
\hline & Bowel Action & & & & & \\
\hline & $<3$ & & $3-6$ & & $>6$ & \\
\hline $\begin{array}{l}\text { Duration of colitis before colectomy } \\
\text { Range } \\
\text { Mean }\end{array}$ & $\begin{array}{l}8 \mathrm{mth}-19 \mathrm{yr} \\
6 \cdot 3\end{array}$ & $\begin{array}{l}(18)^{1} \\
(18)\end{array}$ & $\begin{array}{l}1 \mathrm{mth}-29 \mathrm{yr} \\
6 \cdot 3\end{array}$ & $\begin{array}{l}(46) \\
(46)\end{array}$ & $\begin{array}{l}2 \mathrm{mth}-25 \mathrm{yr} \\
7 \cdot 4\end{array}$ & $\begin{array}{l}\text { (14) } \\
\text { (14) }\end{array}$ \\
\hline $\begin{array}{l}\text { Clinical staging at colectomy } \\
\text { A }(\%) \\
\text { B }(\%) \\
\text { C }(\%) \\
\text { D (\%) }\end{array}$ & $\begin{array}{r}0 \\
76 \\
12 \\
12\end{array}$ & $\begin{array}{r}(0 / 17) \\
(13 / 17) \\
(2 / 17) \\
(2 / 17)\end{array}$ & $\begin{array}{l}21 \\
42 \\
21 \\
16\end{array}$ & $\begin{array}{r}(9 / 43) \\
(18 / 43) \\
(9 / 43) \\
(7 / 43)\end{array}$ & $\begin{array}{r}7 \\
22 \\
57 \\
14\end{array}$ & $\begin{array}{l}(1 / 14) \\
(3 / 14) \\
(8 / 14) \\
(2 / 14)\end{array}$ \\
\hline $\begin{array}{l}\text { Extent of colitis on colectomy specimen } \\
\text { Total }(\%) \\
\text { Extensive }(\%) \\
\text { Left-sided }(\%)\end{array}$ & $\begin{array}{l}76 \\
12 \\
12\end{array}$ & $\begin{array}{r}(12 / 16) \\
(2 / 16) \\
(2 / 16)\end{array}$ & $\begin{array}{r}82 \\
11 \\
7\end{array}$ & $\begin{array}{r}(36 / 44) \\
(5 / 44) \\
(3 / 44)\end{array}$ & $\begin{array}{r}100 \\
0 \\
0\end{array}$ & $\begin{array}{r}(14 / 14) \\
(0 / 14) \\
(0 / 14)\end{array}$ \\
\hline $\begin{array}{l}\text { Histology of colectomy specimen } \\
\text { Active cofitis }(\%)\end{array}$ & 88 & $(14 / 16)$ & 91 & $(40 / 44)$ & 100 & $(14 / 14)$ \\
\hline $\begin{array}{l}\text { Inflammation of rectum at operation } \\
\text { Active clinically }(\%) \\
\text { Active histologically }(\%)\end{array}$ & $\begin{array}{l}83 \\
75\end{array}$ & $\begin{array}{l}(15 / 18) \\
(12 / 16)\end{array}$ & $\begin{array}{l}67 \\
79\end{array}$ & $\begin{array}{l}(30 / 45) \\
(33 / 42)\end{array}$ & $\begin{array}{r}77 \\
100\end{array}$ & $\begin{array}{l}(10 / 13) \\
(11 / 11)\end{array}$ \\
\hline $\begin{array}{l}\text { Staging of colectomy and ileorectal ana } \\
\text { Primary }(\%) \\
\text { Staged }(\%)\end{array}$ & $\begin{array}{l}\text { stomosis } \\
72 \\
28\end{array}$ & $\begin{array}{r}(13 / 18) \\
(5 / 18)\end{array}$ & $\begin{array}{l}67 \\
33\end{array}$ & $\begin{array}{l}(31 / 46) \\
(15 / 46)\end{array}$ & $\begin{array}{l}64 \\
36\end{array}$ & $\begin{array}{l}(9 / 14)^{6} \\
(5 / 14)\end{array}$ \\
\hline $\begin{array}{l}\text { Leakage from site of ileorectal anastom } \\
\text { With leak }(\%)\end{array}$ & $\begin{array}{r}\text { osis } \\
11\end{array}$ & $(2 / 18)$ & 24 & $(11 / 46)$ & 14 & $(2 / 14)$ \\
\hline $\begin{array}{l}\text { Interval since ileorectal anastomosis } \\
\text { Range } \\
\text { Mean }\end{array}$ & $\begin{array}{l}6 \mathrm{mth}-17 \mathrm{yr} \\
6.7 \mathrm{yr}\end{array}$ & $\begin{array}{l}(18) \\
(18)\end{array}$ & $\begin{array}{l}6 \mathrm{mth}-17 \mathrm{yr} \\
7 \cdot 2 \mathrm{yr}\end{array}$ & $\begin{array}{l}(46) \\
(46)\end{array}$ & $\begin{array}{l}2 \mathrm{yr}-5 \mathrm{yr} \\
8 \cdot 0 \mathrm{yr}\end{array}$ & $\begin{array}{l}\text { (14) } \\
\text { (14) }\end{array}$ \\
\hline $\begin{array}{l}\text { Late complications } \\
\text { Intestinal obstruction }(\%) \\
\text { Perianal disease }(\%) \\
\text { Ano-rectal stricture }(\%)\end{array}$ & $\begin{array}{r}22 \\
6 \\
0\end{array}$ & $\begin{array}{l}(4 / 18) \\
(1 / 18) \\
(0 / 18)\end{array}$ & $\begin{array}{r}11 \\
4 \\
9\end{array}$ & $\begin{array}{l}(5 / 46) \\
(2 / 46) \\
(4 / 46)\end{array}$ & $\begin{array}{r}14 \\
7 \\
7\end{array}$ & $\begin{array}{l}(2 / 14) \\
(1 / 14) \\
(1 / 14)\end{array}$ \\
\hline
\end{tabular}

Table IV Comparison of bowel frequency/24 hours with preoperative, operative and postoperative factors in ileorectal anastomosis for ulcerative colitis

1 Number of patients in parentheses from which figures are derived. 


\begin{tabular}{|c|c|c|c|c|c|c|}
\hline & \multicolumn{3}{|c|}{ Sigmoidoscopic Appearance } & \multicolumn{3}{|c|}{ Rectal Biopsy Histology } \\
\hline & Inactive & Mildly Inflamed & Actively Inflamed & Inactive & Mildly Inflamed & Actively Inflamed \\
\hline $\begin{array}{l}\text { Bowel frequency per } 2 \\
0-2 \cdot 9 \\
3-3 \cdot 9 \\
4-4 \cdot 9 \\
5-5 \cdot 9\end{array}$ & $\begin{array}{l}24 \text { hours } \\
2^{1} \\
5 \\
1 \\
4\end{array}$ & $\begin{array}{l}0 \\
3 \\
0 \\
1\end{array}$ & $\begin{array}{l}0 \\
0 \\
2 \\
0\end{array}$ & $\begin{array}{l}0 \\
3 \\
0 \\
3\end{array}$ & $\begin{array}{l}2 \\
1 \\
0 \\
0\end{array}$ & $\begin{array}{l}0 \\
1 \\
1 \\
1\end{array}$ \\
\hline $\begin{array}{l}\text { Inability to delay } \\
\text { defaecation for } 30 \\
\text { min }\end{array}$ & 4 & 2 & 1 & 2 & 0 & 2 \\
\hline $\begin{array}{l}\text { Faecal incontinence } \\
\text { in previous } 12 \text { months }\end{array}$ & & 2 & 0 & 1 & 0 & 1 \\
\hline
\end{tabular}

Table V Comparison of bowel function with activity of rectal inflammation at sigmoidoscopy and on rectal biopsy histology in ileorectal anastomosis for ulcerative colitis at St Mark's Hospital

${ }^{1}$ Number of patients in group

scopy and on rectal biopsy histology, where available, in the patients with ileorectal anastomosis for ulcerative colitis seen at St Mark's Hospital. There was no obvious association between bowel frequency, urgency of defaecation or faecal incontinence and rectal inflammation, either sigmoidoscopically or on biopsy at the time of study, although some patients linked deterioration in bowel function historically with episodes of rectal bleeding.

Of the patients with ileorectal anastomosis for colonic polyposis, $36 \%$ had some rectal polyps at the time of study, although their bowel function was indistinguishable from the rest of the group.

In the dietary part of the study, $98 \%$ of the colitic group and $91 \%$ of the polyposis group said that their weight was steady or increasing. Of the six patients who said they were losing weight, both in the colitic group and two of the four in the polyposis group, were on reducing diets. In the colitic group, $11 \%$ said they had difficulty in choosing a diet, compared with $16 \%$ of the polyposis group. Eighteen per cent of the colitic group and $7 \%$ of the polyposis group had no bowel symptoms with any item of diet and $67 \%$ in each group had identified five or fewer items of diet which upset them.

Table VI shows the effect of individual items of diet on bowel function in the two groups. Bowel symptoms were produced in more than $20 \%$ of patients in the colitic group by baked beans, onions, lettuce, apples, rhubarb and beer and in more than

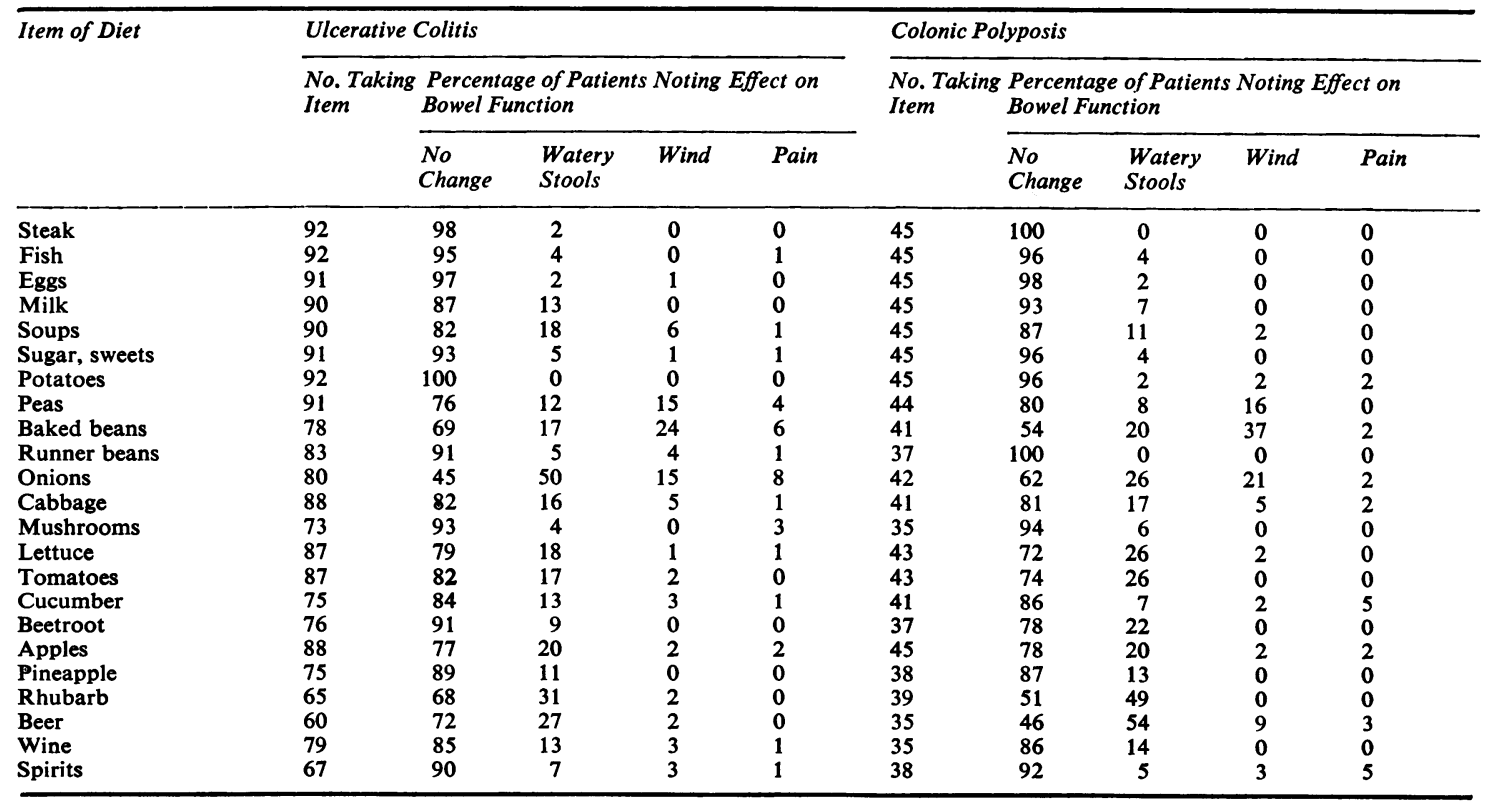

Table VI Effect of individual items of diet on bowel function after ileorectal anastomosis 
$20 \%$ of the polyposis group by baked beans, onions, lettuce, tomatoes, beetroot, apples, rhubarb and beer. Watery stools were the most common symptom, but wind was also a prominent complaint in both groups after peas, baked beans and onions. Watery stools after milk ingestion were noted by $13 \%$ of the colitic group and $7 \%$ of the polyposis group. A further patient in the polyposis group noted a marked reduction in bowel frequency on a milk-free diet, although she had not previously associated milk ingestion with her frequent stools. A very wide variety of other foods produced bowel symptoms in a few patients.

\section{Discussion}

This study compares bowel function in outpatients with ileorectal anastomosis for ulcerative colitis and colonic polyposis. It inevitably excludes those who have died, those treated by definitive ileostomy and those subsequently converted to ileostomy. No attempt has been made to determine the ratio of ileorectal anastomosis to definitive ileostomy operations performed in either hospital as there were no accepted criteria for ileorectal anastomosis and many patients were referred specifically for this operation. Operative mortality and conversions to ileostomy among colitics treated by ileorectal anastomosis have been reported from both St Mark's Hospital (Baker, 1970) and the Gordon Hospital (Aylett, $1966,1971)$ and are outside the scope of this study.

To avoid the possibility of selecting a particularly favourable group of outpatients from among those who retain their ileorectal anastomosis, an attempt was made to see all eligible patients, who were attending follow up at St Mark's or the Gordon Hospital during the time of the study. Although only $68 \%$ of the patients with ileorectal anastomosis for ulcerative colitis were seen, the results of the analysis of hospital notes show that over $80 \%$ of these patients had total colitis active at the time of colectomy and little difference was found between those seen and those not seen. We therefore believe that, despite the limitations, this study provides a valid assessment of bowel function six months or more after ileorectal anastomosis for ulcerative colitis.

It confirms that the average bowel frequency after ileorectal anastomosis for ulcerative colitis is four to five stools per 24 hours. Average bowel frequency after ileorectal anastomosis for colonic polyposis is a little less at three to four stools per 24 hours, but the range of individual variation is almost identical in the two groups. Urgency of defaecation is not a problem in the majority of patients, but some bowel actions at night and occasional faecal incontinence are probably an inevitable result of anastomosis of the ileum to the rectum in some patients. Many more patients in the colitic group take treatment regularly to improve bowel function, but as they often have a long history of medical therapy for colitis preoperatively, they may accept treatment more readily than the polyposis patients, who have usually had no drug therapy before the ileorectal anastomosis.

The comparison of bowel frequency in the colitic group with preoperative, operative and postoperative factors suggests that patients in poor general condition at the time of colectomy are more likely to have over six bowel actions per 24 hours after ileorectal anastomosis than less severely ill patients, although the number of patients in this bowel frequency group was small and two-thirds of the patients who had been in poor general condition had six or fewer bowel actions per 24 hours at the time of study. No other factor of prognostic significance was identified. On examining the same factors in the small number of patients with urgency of defaecation or faecal incontinence, the only possibly relevant factor identified was the presence of an ano-rectal stricture, which seems to be associated with incontinence in some patients. The presence of rectal inflammation, either at the time of anastomosis or at the time of study in the small number of patients where this information was available, did not seem to be associated with any particular aspect of bowel function.

Nutrition, as assessed by steady or increasing weight or intentional slimming, is adequate in almost all patients who have had an ileorectal anastomosis for six months or more. Dietary difficulties after the operation are uncommon and reactions to individual foods are very similar after ileorectal anastomosis for ulcerative colitis and colonic polyposis. The results of the dietary study are very similar to those obtained by Thomson et al (1970) in a study of ileostomists, although the number of patients with dietary problems in this survey is too small to analyse for differences in sex or time since operation as they did. The incidence of milk intolerance is comparable with the incidence of lactase deficiency described for a Caucasian population by Newcomer and McGill (1967). It is not always recognized by the patient and experience in this study suggests, as in the study of Gudmand-Høyer and Jarnum (1970), that trial of a milk-free diet is worthwhile in patients who complain of watery stools after ileorectal anastomosis.

We are very grateful to $\mathrm{Mr}$ S. O. Aylett of the Gordon Hospital and all the surgeons of St Mark's Hospital for their kind cooperation in allowing us 
to study their patients without restriction. We are also very grateful to Dr J. E. Lennard-Jones for his helpful advice and criticism.

\section{References}

Aylett, S. O. (1966). Three hundred cases of diffuse ulcerative colitis treated by total colectomy and ileo-rectal anastomosis. Brit. med.J., 1, 1001-1005.

Aylett, S. O. (1970). Delayed ileorectal anastomosis in the surgery of ulcerative colitis. Brit.J. Surg., 57, 812-813.

Aylett, S. O. (1971). Ileorectal anastomosis: review 1952-1968. Proc. roy. Soc. Med., 64, 967-971.

Baker, W. N. W. (1970). The results of ileorectal anastomosis at St Mark's Hospital from 1953 to 1968. Gut, 11, 235-239.

Boehme, E. J. (1950). The surgical treatment of familial polyposis of the colon. Ann. Surg., 131, 519-533.

Clemmesen, T., and Sprechler, M. (1970). Twenty years experience with colectomy and ileorectal anastomosis in the treatment of ulcerative colitis. In Advance Abstracts, 4 th World Conference of Gastroenterology, Copenhagen, Denmark, p. 485.

Ewart, W. B.. and Lennard-Jones, J. E. (1960). Corticosteroids in preoperative medical management of ulcerative colitis. Do they affect surgical success? Lancet, 2, 60-64.

Gudmand-Høyer, E.. and Jarnum, S. (1970). Incidence and clinical significance of lactose malabsorption in ulcerative colitis and Crohn's disease. Gut, 11, 338-343.

Jagelman, D. G., Lewis, C. B., and Rowe-Jones, D. C. (1969). Ileorectal anastomosis: appreciation by patients. Brit. med. J., 1, 756-757.

Lockhart-Mummery, H. E., Dukes, C. E., and Bussey, H. J. R. (1956) The surgical treatment of familial polyposis of the colon. Brit. J. Surg., 43, 476-481.

Nedbal, J., Maratka, Z., and Novak, J. (1970). The late course of patients with proctocolitis after ileorectal anastomosis and colectomy. In Advance Abstracts, 4th World Conference of Gastroenterology, Copenhagen, Denmark, p. 488.

Newcomer, A. D.. and McGill, D. B. (1967). Disaccharidase activity in the small intestine: prevalence of lactase deficiency in 100 healthy subjects. Gastroenterology, 53, 881-889

Thomson, T. J., Runcie, J., and Khan, A. (1970). The effect of diet on ileostomy function. Gut, 11, 482-485.

Watts, J. McK., and Hughes, E. S. R. (1970). Ileorectal anastomosis for ulcerative colitis: an assessment of the late results by an independent observer. In Advance Abstracts, 4th World Conference of Gastroenterology, Copenhagen, Denmark, p. 229.

Williams, J. L.. and Wightman, J. A. K. (1966). Familial polyposis of the colon. Report of a family with 5-year follow-up of colectomy and ileorectal anastomosis. Brit. J. Surg., 53, 780-784. 